\title{
A Survey of the Patient's Safety Culture Among Nurses in Tehran-Based Hospitals Affiliated with Social Security Organization - 2013-2014
}

\author{
Zahra Hashemi Dehaghi, ${ }^{1, \text {, }}$ \\ ${ }^{1}$ School of Management, Department of Management and Accounting, Islamic Azad University, South Tehran Branch, Tehran, Iran \\ ${ }^{2}$ Eye Research Center, Tehran University of Medical Sciences, Tehran, Iran
}

\section{Email address:}

Hashemi_mitra@yahoo.com

\section{To cite this article:}

Zahra Hashemi Dehaghi. A Survey of the Patient's Safety Culture Among Nurses in Tehran-based Hospitals Affiliated with Social Security Organization- 2013-2014. Journal of Human Resource Management. Vol. 4, No. 1, 2016, pp. 6-9. doi: 10.11648/j.jhrm.20160401.12

\begin{abstract}
The patient's safety culture refers to priority of the patient's safety in the eyes of health and treatment staff. Without it, permanent development of health care system is not possible. The present study is aimed at analyzing patient's safety culture status from nurses' viewpoint. The descriptive-correlative study was carried as cross sectional work in the selected hospitals affiliated with Social Security Organization in 2013 and early 2014. Study population was comprised of all nurses working in the selected hospitals and a sample group $(\mathrm{n}=200)$ was selected through random sampling. A standard questionnaire of patient's safety culture was used for gleaning the data. SPSS was used to analyze the data using mean, standard deviation, t-test, and the Pearson's correlation coefficient. Among the aspects of the questionnaire, the respondents assigned the highest point to "teamwork attitude among different units" (mean and SD $=4.01 \pm 0.97$ ) followed by "organizational learning-permanent improvement" (mean and SD $=4.05 \pm 0.75$ out of 5); and the aspects "employees' issues" (mean and SD =2.20 \pm 1.10 ) and "punitive measure in response to error" (mean and SD $=2.52 \pm 0.98$ out of 5) obtained minimum points. According to the Pearson's correlation test, there was a significant correlation between age and work record on one hand and "teamwork attitudes among different wards" on the other hand. Apparently, safety culture needs revision in some areas and training, cultural works, providing supportive organizational environment, and improving motivating environmental factors are of the main measures that can be taken by the managers to this end.
\end{abstract}

Keywords: Patient's Safety Culture, Safety, Nurse, Hospital

\section{Introduction}

The patient's safety is one of key elements of quality of a health system [1]. Expectedly, it has drawn great deal of attention in the recent decades in different countries [2]. Being safe from risks, threats and harms while receiving health services is one of most basic rights of patients [3]. Medical errors, on the other hand, are one of the main challenges ahead of health systems in every country [4]. The idea that health systems are not safe enough and need improvements in this regard has been pushed forward in the last two decades. On the other hand, developments and new achievements in the field of patient's safety have enabled health providers to detect the risks and threats and find ways to deal with them. However, the point is that without promoting safety culture in all health and treatment facilities, no major and stable improvement in patient's safety is expected. [5].

The patient's safety, todays, is one of the first priorities in clinical health care services. Medical Association recommended that all health care centers should try to improve the patient's safety through improving organizational culture aspects [6]. According to the available evidences, problems raised by poor safety measures are mainly rooted in systemic organizational matters and individual errors constitute small portion of the problem [7, 8]. Among the features of such culture are trying not to conceal errors and incidents and reporting them instead, the patient's safety training, availability of error reporting system, employing data from reporting system to improve processes, promoting teamwork attitudes, avoiding blaming employees, establishing transparent relationships between the wards, promoting cooperative attitudes among colleagues in 
line with interests of the patients, and top manager's attention to safety issues [9].

As recommended by other studies, adopting systemic approach to medical errors and removing the shortcomings needs changes in organizational safety culture and systems (including incidents reporting system). This increases the patient's safety and effectiveness of clinical services, which in turn leads to increase of performance of the management and decrease of medical costs. Implementation of a systemic approach through preventing errors results in reduction of hospitalization term, amount of medicine consumed, necessity of further medical attentions due to side effects, and reduction of secondary medical and hospitalization costs. [10,11]

It is estimated that around 239000 Medicare patients were died in the SUA between 2004 and 2006 due to preventable medical errors. Number of medical care deaths in Canada is 24000 each year [12]. In addition to mortality rate or inabilities, these errors are too costly. As the reports indicate, medical errors under Medicare plan cost 8.8 billion dollars in the USA between 2004-2006 [13].

While, majority of works done until now to cut medical errors have been actually a reaction to a problem, a great potential to improve the patient's safety lies in detecting and removing risks before incidents take place [14]. To be successful in the area, the patient's safety must be considered as an organizational priority as if it is the centerpiece of all affairs. [15]

As recommended by other studies, hospitals with better safety environment encounter fewer problems as to patients' safety [16]. Therefore, it is imperative to improve patient's safety culture and transfer from the culture in which no error and incident is reported to the culture that motivates reporting errors even when no harm is received by the patient [17]. To this end, to improve the patient's safety culture, and in turn improve quality of health services and remove probable problems, the patient's safety culture needs to be determined first. In light of this, the present study attempts to survey the patient's safety culture in the eyes of the nurses working in health centers affiliated with Social Security Org. in Iran in 2013-2014.

\section{Methodology}

The data were collected from the nurses working in Tehran-based hospitals affiliated with Social Security Org. (Ayatollat Kashani, Shahdi Labafinejad, Hedayat, Fayazbakhsh, and Sadr Behafarin). The study was carried out as a descriptive, analytical, cross-sectional work. Gleaning information included multi-stage random sampling relative to nurses' population size. Questionnaires were handed over to 200 nurses and all the participants were ensured that their information would be reported under the condition of anonymity. The questionnaire used to this end was a standard patient's safety culture designed by Quality and Health Care Research Agency. Cronbach alpha of internal correlation of all aspects was 0.85 and Spearman Brown coefficient was 0.81 . The questionnaire includes 12 aspects including "easy communication (3 questions)", "communication and feedback regarding errors (3 questions)", "transferring patient" (5 questions)", “top managers' support (3 questions)", "non-punitive response to errors (3 questions)", organizational learning and permanent improvement (3 questions)", "general perception of patient's safety (4 questions)", “employees' issues (4 questions)", "manager/supervisor's expectation (4 questions)", "teamwork among wards (4 questions)", "teamwork among units (tree questions), and "routine incident reports (4 questions)." The statement were scored based in Likert's five-point scale (1 = completely disagree, $\ldots .5=$ completely agree) with maximum and minimum points equal with 160 and 0 respectively. In addition, there were 11 demographic information questions (age, gender, marital status, organizational post, work record, place of service). Average point of $75 \%$ of the responses was 3.70 out of 5 and $50 \%$ of the responses were scored less than 2.5 out of 5 . Statistical analyses were carried with confidence level of $95 \%$ and estimate error of 0.05 . Analyses were conducted using descriptive statistics, t-test, one-way variance, and the Pearson's correlation. As the results showed, there was no significant difference between average point of the 12 aspects of safety culture and demographical information.

\section{Findings}

Due to the important role played by nurses in the patient's safety culture, majority of the participants were nurses. Mean and standard deviation of the participants' age was $33 \pm 8$ and $63 \%$ of them were under 34 years old. Moreover, $97 \%$ were women and $69 \%$ were married; $85 \%$ had bachelors' degree; 6.5\% (9) were assistants and 7.5\% (11) were supervisors. Finally, $44.4 \%$ of the participants worked in intense care wards. (Table 1)

Table 1. Demographic information of the participants.

\begin{tabular}{llll}
\hline Variables & & N & \% \\
\hline \multirow{2}{*}{ Gender } & M & 6 & 2.9 \\
& F & 194 & 97.1 \\
Age & $24-20$ & 24 & 11.1 \\
& $29-25$ & 53 & 24 \\
Marital status & $34-30$ & 66 & 30.2 \\
& $39-35$ & 22 & 10 \\
Organizational position & More than 40 & 51 & 23.8 \\
& Unmarried & 60 & 31 \\
& Married & 140 & 69 \\
& Supervisor & 11 & 7.5 \\
& Nurse & 149 & 85.5 \\
& Assistant & 9 & 6.5 \\
Work record (year) & Less than 5 & 75 & 39.5 \\
& $5-10$ & 52 & 27.5 \\
& $10-15$ & 17 & 9 \\
& $15-20$ & 23 & 11.1 \\
\hline
\end{tabular}

Among the 12 aspects of the questionnaire, "teamwork 
attitude among the units" (mean and SD $=4.10 \pm 0.97)$ and "organizational learning-permanent improvement" (mean and $\mathrm{SD}=4.05 \pm 0.75$ out of 5 ) obtained the highest point; and the aspects "employees' issues" (mean and SD = 2.20 \pm 1.10 ) and "punitive measure in response to error" (mean and SD = $2.52 \pm 0.98$ out of 5 ) obtained minimum points. (Table 2 )

Table 2. Mean points based on aspects of the patient's safety culture.

\begin{tabular}{ll}
\hline Aspects & Mean and SD \\
\hline teamwork among wards & $0.94(3.54)$ \\
manager/supervisor's expectation & $0.90(3.3)$ \\
top managers' support & $0.95(3.35)$ \\
organizational learning and permanent improvement & $0.75(4.05)$ \\
general perception of patient's safety & $1.01(3.15)$ \\
communication and feedback regarding errors & $0.80(3.79)$ \\
easy communication & $1.05(3.62)$ \\
routine incident reports & $1.01(2.90)$ \\
teamwork among units & $0.97(4.01)$ \\
Employees' issues & $1.10(2.20)$ \\
transferring patient & $1.05(3.40)$ \\
non-punitive response to errors & $0.98(2.52)$ \\
\hline
\end{tabular}

The results showed that $26 \%$ of the respondents believed that no accident has been reported over the past year, $42 \%$ stated that 1 to 2 accidents have been reported in their ward, and 5\% did not answer the question. These reports show that reporting system of the hospitals needs improvements.

\section{Discussion and Conclusion}

Mean point of safety culture in the hospitals under study was $66.5 \%$, which is consistent with Rezapour et al. [18]. The highest points were given to the aspects "organizational learning and permanent improvement" and "teamwork attitudes among units", which indicates that training and permanent improvement programs have been implemented in the studied hospitals. Teamwork attitude among colleagues was another advantage of the participation; which is consistent with other studies [1]. Teamwork attitude within and among the wards was also satisfactory; $71 \%$ believed in teamwork attitudes in their ward and $53 \%$ believed in teamwork attitudes between the wards. One may concludes that the reason for frequent errors in the past was lack of coordination among the wards and a sort of individualistic culture. Through teamwork, the staff has the opportunity of having their works supervised by their colleagues, which is great help in preventing medical errors. On the other hand, providing health services is teamwork in nature. Rozoski and Woods maintained that teamwork reduces probability of personnel's errors. Within teamwork framework, immense volume of assignment and risk of errors caused by tiredness is replaced with new responsibility to keep good relationship with other team members [16]. As to the aspect "easy communication" $50.1 \%$ of the participants believed that they can easily communicates with their colleagues and $42.1 \%$ believed that they would be informed if an error is made. Hostchinson et al concluded that there was a significant relationship between reporting accidents and independent indices of the patient's safety culture and increase of reporting has positive effects on development of safety culture in hospitals. [20]

Moreover, $40 \%$ of the respondents expressed that the manager only pays attention to safety matters when something goes wrong seriously and only $17 \%$ of the respondents believed that the management has failed to provide proper environment for improvement of the patient's safety. This shows that the responsibility of providing a safe environment for the patients is critical and managers at different levels has a role to play in designing a proper program and prepare a decent environment based on safety program principle to minimize effects of errors. Zaboli et al. emphasized in their study on the role of management in creating a secure environment for the patients and introducing proper safety programs to the employees [21]. There is a general agreement among the managers that repetition of preventable errors and risking safety of the patient are in contrary with preliminary mission of the healthy system. In addition, adopting a systematic approach to medical errors not only improves patients' safety and effectiveness of clinical services, but also is a great improvement in management's performant and cutting the costs.

Another aspects that obtained low points was "employees' issue" $(25 \%)$, which is consistent with Chen and $\mathrm{Li}(39 \%)$ and Alahmadi (27\%). This shows that clinical service section is understaffed $[22,23]$. Lack of enough human force has been reported by many studies as one of the common problems from the nurses' viewpoint [24, 25]. Apparently, managers need to reevaluate safety culture of hospital and focus more on preventive programs.

The results showed significant negative correlation between age and work report on one hand and teamwork attitudes among the wards (age $\mathrm{r}=-0.20$; work report $\mathrm{r}=0.22$; $\mathrm{p}<0.001$ ); so that point of this aspect decreases with increase of age and work record, which means increase of experience of the nurses and their familiarity with hospital culture.

There are several approaches to improve the patient's safety culture in hospitals and education is one of the key ones. Many participants indicated training about the patient's safety and medical error as a critical factor in improving the staff's knowledge and awareness. Another approach is establishment of a safety committee in the hospital. Such committee can acts as the authority to give needed training to the supervisors and managers of the wards, survey reported errors (in a cooperation with quality control and quality improvement departments), detect probable causes of the errors, and take required measures to avoid the errors. In general, the main purpose of hospitals and medical centers is to accelerate treatment process and improve health of the referrals. However, in some occasions, the patient suffers injuries and harms throughout the treatment process. Detecting and reducing risk of such injuries and errors is one of the top priorities of all health centers that are aimed at offering quality health services. Therefore, this area needs more attentions from managers and authorities of health centers. To this end, cultural works and providing 
environmental incentives are of the main steps that should be taken by hospitals authorities.

\section{Acknowledgement}

The authors express their gratitude toward all authorities and nurses in Tehran-based hospitals affiliated with Social Security Organization and all others who helped to carry out this study.

\section{References}

[1] Smits M, Christiaans I, Wagner C, van der Wal G, Groenewegen P. The psychometric properties of the 'Hospital Survey on Patient Safety Culture' in Dutch hospitals. BMC Health Services Research 2008; 8: 230-39.

[2] Bodur S, Filiz E. Validity and reliability of Turkish version of -Hospital Survey on Patient Safety Culturell and perception of patient safety in public hospitals in Turkey. BMC Health Services Research 2010; 10: 28.

[3] Aboul-Fotouh AM, Ismail NA, Ez Elarab HS, Wassif GO. Assessment of patient safety culture among healthcare providers at a teaching hospital in Cairo, Egypt. East Mediterr Health J. 2012 Apr; 18 (4): 372-7.

[4] Goodman GR. A fragmented patient safety concept: the structure and culture of safety management in healthcare. Hospital Topics. 2003; 81 (2): 22.

[5] Lange JF, Dekker-van Doorn CM, Haerkens MH, Klein J. A safety culture in hospitals. Ned Tijdschr Geneeskd. 2011; 155: A2253.

[6] Ilan R, Fowler R. Brief history of patient safety culture and science. J Crit Care. 2005 Mar; 20 (1): 2-5.

[7] Keady S, Thacker M. National Patient Safety Agency: improving patient safety across all critical care areas. Intensive Crit Care Nurs. 2008 Apr; 24 (2): 137-40.

[8] Milligan JF. Establishing a culture for patient safety-the role of education. Nurse Education Today 2007; 2: 95-102.

[9] Schutz LA, Counte AM, Meurer S. Development of a patient safety culture measurement tool for ambulatory health care settings: analysis of content validity. Health Care Management Science 2007; 2: 139-49.

[10] Dalton GD, Samaropoulos XF, Dalton AC. Improvements in the safety of patient care can help end the medical malpractice crisis in the United States. Health Policy. 2008 May; 86 (2-3): 153-62.

[11] Shah S, Patch M, Pham JC. Systems Approach to Patient Safety. Injury Research. 2012; pp 583-597.
[12] Woolhandler S, Campbell T, Himmelstein D. 2003. Costs of Health Care Administration in the United States and Canada. N Engl J Med. 2003; 349: 768-75.

[13] Sharma G, Awasthi S, Dixit A, Sharma G. Patient safety risk assessment and risk management: A review on Indian hospitals. 2011; 2(4): 186-91.

[14] Reson J. 2000. Managing the risk of organizational accident. Burlington.

[15] Pronovost PJ, Weast B, Holzmueller CG, Rosenstein BJ, Kidwell RP, Haller KB, et al. Evaluation of the culture of safety: survey of clinicians and managers in an academic medical center. Qual Saf Health Care. 2003; 12 (6): 405-10.

[16] Zohar D, Livne Y, Tenne-Gazit O, Admi H, Donchin Y. Healthcare climate: a framework for measuring and improving patient safety. Crit Care Med. 2007 May; 35 (5): 1312-7.

[17] Wilson KA. Dose safety culture predicts clinical outcomes? Florida: University of Central Florida.

[18] Rezapoor A, Tanoomand Khoushehmehr A, Bayat R, Arabloo J, Rezapoor Z. [Study of patients' safety culture in Selected Training hospitals affiliated with Tehran university of medical sciences.] Hospital. 2012; 11 (2): 55-64.

[19] Marshall DA, Manus DA. A team training program using human factors to enhance patient safety. AORN J. 2007 Dec; 86 (6): 994-1011.

[20] Hutchinson A, Young TA, Cooper KL, McIntosh A, Karnon JD, Scobie S, et al. Trends in healthcare incident reporting and relationship to safety and quality data in acute hospitals: results from the National Reporting and Learning System. Qual Saf Health Care. 2009 Feb; 18 (1): 5-10.

[21] Zaboli R, Tofighi SH, Delavari A, Mirhashemi S. Survey of Safety management on Bagiyatallah (a. s) Hospital, 2006-07. J Military Med. 2007; 9 (2): 1 03-11.

[22] Alahmadi H. Assessment of patient safety culture in Saudi Arabian hospitals. Qual Saf Health Care. 2010; 19 (5): 1-5.

[23] Chen I-C, Li H-H. Measuring patient safety culture in Taiwan using the Hospital Survey on Patient Safety Culture (HSOPSC). BMC Health Serv Res. 2010; 10 (1): 152.

[24] Dehghan nayeri N, Nazari AA, Salsali M, Ahmadi F. [Work force role in nursing productivity: qualitative research]. Hayat. 2006; $12(3): 5-15$.

[25] Rostami H, Montazam H, Ghagramanian A, Mirghafoorvand M. [nurses' and patients' viewpoint about patient education barriers]. Scientific Journal of Hamadan Nursing \& Midwifery Faculty. 2010; 18 (1): 50-5. 